\title{
Aortic balloon valvuloplasty as a bridge to liver transplantation in a patient with severe aortic stenosis and end-stage liver disease
}

\author{
(D) Vlado-Vlaho Ćubela', \\ (D)Maro Dragičevićć, \\ DDoško Bulum ${ }^{2,3}$, \\ (DTajana Filipec \\ Kanižaj ${ }^{1,3}$, \\ (iD) Helena Jerkić1,3*
}

'University Hospital "Merkur", Zagreb, Croatia

2University Hospital Centre Zagreb, Zagreb, Croatia

${ }^{3}$ University of Zagreb, School of Medicine, Zagreb, Croatia
RECEIVED:

July 15, 2021

ACCEPTED:

August 5, 2021
KEYWORDS: balloon aortic valvuloplasty, aortic stenosis, end-stage liver disease, orthotopic liver transplantation.

CITATION: Cardiol Croat. 2021;16(9-10):289. | https://doi.org/10.15836/ccar2021.289

*ADDRESS FOR CORRESPONDENCE: Helena Jerkić, Klinička bolnica Merkur, Zajčeva 19, HR-10000 Zagreb, Croatia. / Phone: +385-99-4888-576 / E-mail: helenajerkic@yahoo.com

ORCID: Vlado-Vlaho Ćubela, https://orcid.org/0000-0002-5664-1873 • Maro Dragičević, https://orcid.org/0000-0002-2620-3194 Joško Bulum, https://orcid.org/0000-0002-1482-6503 • Tajana Fllipec Kanižaj, https://orcid.org/0000-0002-7025-0932 Helena Jerkić, https://orcid.org/0000-0002-1650-4735

|I|||||||||||||||||||||||||||||||||||||||||||||||||||||||||||||||||||||||||||||||||||||||||||||||||||||||||||||||||||||||||||

Introduction: Severe aortic stenosis (AS) in patients with end-stage liver disease (ESLD) increases the morbidity and mortality of orthotopic liver transplantation (OLT). OLT is a surgical intervention with serious hemodynamic changes which can contribute to heart failure and cardiac death. Due to increased perioperative mortality, severe AS and ESLD are considered contraindications for OLT or aortic valve replacement $(A V R)^{1}$. Aortic balloon valvuloplasty (BAV) may be a reasonable therapeutic option to improve the hemodynamic status and enable OLT2

Case report: The patient was a 43-year-old female who had an OLT in 2019 due to fulminant hepatitis B. AS was detected in 2018 and it progressed to severe in 2021. In 2021, another decompensation of cirrhosis of the liver graft occurred. The patient had Child-Pugh B graft cirrhosis which is according to the available data, contraindication for cardiac surgery ${ }^{3}$. A multidisciplinary meeting was held and it was decided to do a BAV as a less invasive procedure before OLT. BAV was made with a satisfactory reduction of the transvalvular pressure gradient by $30 \%$ and with this procedure, the patient is hemodynamically in a more favorable position for OLT.

Discussion: BAV was presented as a minimally invasive procedure with fewer complications to surgical replacement for AS in patient with ESLD. In practice, the procedure was proved to have a high percentage of complications and only a modest hemodynamic upgrade compared with AVR. Therefore, valvuloplasty should not be the first choice for AS. However, there are some indications for BAV such as a palliative treatment and in patients with AS and ESLD as a bridging procedure to OLT ${ }^{1}$. This procedure enabled our patient to undergo surgery in a hemodynamically more favorable situation. It is also necessary to say that a multidisciplinary approach involving gastroenterologists, cardiologists, cardiac and abdominal surgeons, and anesthesiologists is the key in the treatment of such patients. In conclusion, in patients who are unsuitable for OLT because of AS, BAV, and then OLT may be a good approach that permits AVR posttransplantation. However further research is needed to demonstrate the advantages and disadvantages of this approach.

LITERATURE IIIIIIIIIIIIIIIIIIIIIIIIIIIIIIIIIIIIIIIIIIIIIIIIIIIIIIIIIIIIIIIIIIIIIIIIIIIIIIIIIIIIIIIIIIIIIIIIIII

1. Kalarickal P, Liu Q, Rathor R, Ishag S, Kerr T, Kangrga I. Balloon aortic valvuloplasty as a bridge to liver transplantation in patients with severe aortic stenosis: a case series. Transplant Proc. 2014;46(10):3492-3495. https://doi.org/10.1016/j.transproceed.2014.08.035

2. Coverstone E, Korenblat K, Crippin JS, Chapman WC, Kates AM, Zajarias A. Aortic balloon valvuloplasty prior to orthotopic liver transplantation: a novel approach to aortic stenosis and end-stage liver disease. Case Rep Cardiol. 2014;2014:325136. https://doi.org/10.1155/2014/325136

3. Jacob KA, Hjortnaes J, Kranenburg G, de Heer F, Kluin J. Mortality after cardiac surgery in patients with liver cirrhosis classified by the ChildPugh score. Interact Cardiovasc Thorac Surg. 2015;20(4):520-530. https://doi.org/10.1093/icvts/ivu438 